\title{
Octovien De Saint-Gelais, Le Séjour d'Honneur
}

\section{Gianni Mombello}

\section{(2) OpenEdition}

\section{Journals}

\section{Édition électronique}

URL : https://journals.openedition.org/studifrancesi/37317

DOI : $10.4000 /$ studifrancesi.37317

ISSN : 2427-5856

\section{Éditeur}

Rosenberg \& Sellier

\section{Édition imprimée}

Date de publication : 15 décembre 2004

Pagination : $585-586$

ISSN : 0039-2944

\section{Référence électronique}

Gianni Mombello, «Octovien De Saint-Gelais, Le Séjour d'Honneur», Studi Francesi [En ligne], 144 (XLVIII | III) | 2004, mis en ligne le 30 novembre 2015, consulté le 08 mai 2021. URL : http://

journals.openedition.org/studifrancesi/37317 ; DOI : https://doi.org/10.4000/studifrancesi.37317

\section{Ce document a été généré automatiquement le 8 mai 2021.}

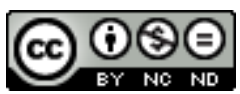

Studi Francesi è distribuita con Licenza Creative Commons Attribuzione - Non commerciale - Non opere derivate 4.0 Internazionale. 


\title{
Octovien De Saint-Gelais, Le Séjour d'Honneur
}

\author{
Gianni Mombello
}

\section{RÉFÉRENCE}

ocTOVIEN DE SAINT-GELAIS, Le Séjour d'Honneur. édition critique, introduction et notes par

Frédéric DUVAL, Genève, Droz, 2002 («Textes Littéraires Français», 545), pp. 534.

1 En 1977 Joseph Alston James publiait, dans le volume 181 de la collection du «Department of Romance Language» de l'Université du North Carolina (Chapel Hill), une édition hâtive du Séjour d'Honneur. Les limites de ce travail ont été signalées par de nombreux comptes rendus mentionnés par Fr. Duval (p. 9, n. 2) auxquels il faut ajouter aussi celui qui a paru dans «Studi Francesi» (XXII, 2-3, 1978, p. 462). Il fallait donc refaire cette édition et Frédéric Duval s'est chargé de cette tâche avec des résultats excellents.

Le nouvel éditeur démontre de bien connaître l'auteur, le milieu social et littéraire dans lequel il a vécu, tous ses écrits et la bibliographie le concernant.

3 L'introduction, divisée en six chapitres, est importante (pp. 11-111) et elle nous renseigne pertinemment sur Octovien de Saint-Gelais, sur sa production littéraire (I) et sur la date de composition du Séjour d'Honneur (en gestation peut-être depuis 1489, mais rédigé de 1491 à 1492, avec des ajouts postérieurs) (II).

4 Le commentaire littéraire (III) est tout aussi important (pp. 21-51). Frédéric Duval essaie de saisir le sens de cette œuvre en partant des analyses déjà anciennes de H. Guy (1908) et de H.-J. Molinier (1910) et en mettant à contribution les études succesives et assez nombreuses qu'il examine, approfondit et complète.

5 On part du titre bien intégré à l'œuvre. Ce quasi-songe (p. 38) est une œuvre d'édification dans laquelle le jeu moral l'emporte sur le jeu verbal (p. 23) cher aux Grands Rhétoriqueurs. Si Honneur représente Charles VIII, son séjour n'est pas 
seulement sa cour, vers laquelle les «erreurs» de la jeunesse avaient poussé l'auteur. A travers de fort nombreuses péripéties, l'«acteur» parvient enfin dans l'ernitage d'Entendement et y trouve le véritable séjour d'honneur qui est, en même temps, la cour royale et le bien moral. Les nombreux exemples et les thèmes rebattus, qui s'égrainent dans ce prosimètre, sont détournés pour qu'ils aboutissent à une leçon morale: signaler le chemin qui conduit vers le vrai bonheur. Il s'agit donc d'un pèlerinage initiatique.

6 Dans la quatrième partie de l'introduction sont passés en revue les témoins qui nous ont transmis cette œuvre: deux manuscrits: BnF, fr. 1196 (= B) et fr. 12'783 (= A) et trois éditions toutes parisiennes (Antoine Vérard, c. $1503=$ a; [Germaine Guyart], $1519=$ b; [Veuve Trepperel], c. 1519-1520 = c), dont les leçons sont analysées et comparées. Il en ressort un stemma bifide dans lequel A et B s'opposent et le premier engrendre $\mathrm{a}, \mathrm{b}$ et $\mathrm{c}$, per l'intermédiaire de $\alpha$ et $\beta$ non survécus.

7 Le texte de base choisi est A corrigé sur a et b et ensuite sur B. Seul l'accord de B avec a et $b$ justifie le rejet de la leçon de $A$.

8 Suit une étude linguistique détaillée du Séjour d'Honneur et donc de A. L'orthographe floue de cette époque suscite de redoutables problèmes d'interprétation, non seulement au niveau de la phonétique, mais aussi de la morphologie et de la syntaxe. Les contradictions sont nombreuses, mais Frédéric Duval se tire avec aisance de toute ces embûches, en nous proposant une revue claire et détaillée de la langue et de la versification de cette œuvre. Le fait de constater qu'Octovien de Saint-Gelais ne s'éloigne pas du standard de la fin du $\mathrm{XV}^{\mathrm{e}}$ siècle, n'enlève en rien à l'intérêt de ces pages.

9 Le vocabulaire du Séjour d'Honneur a fait l'objet d'un article paru dans la «Revue de Linguistique Romane», en 2001 (cf. la fiche précédente), toutefois, cette édition est munie d'un glossaire substantiel et riche (pp. 443-504) qui signale, entre autres, les premières attestations et donne des renvois fort utiles aux notes critiques.

10 Ces dernières sont abondantes et fort savantes (pp. 409-442). Elles ne concernent pas seulement le lexique et la langue en général, mais elles sont riches en notices historiques et littéraires et surtout en de nombreux et fort pertinents renvois à d'autres œuvres d'Octovien de Saint-Gelais.

11 Le volume s'achève par un index des noms propres et des personnifications (pp. 505-31) et par une table de concordances (533-34) avec l'édition James.

Il ne reste qu’à féliciter Frédéric Duval pour cette réussite. 